\section{SAT0201 ASSOCIATION OF CARDIAC TROPONIN T MEASURED WITH A HIGHLY SENSITIVE ASSAY WITH CARDIOVASCULAR EVENTS IN PATIENTS WITH SYSTEMIC LUPUS ERYTHEMATOSUS (TROPOPLUS STUDY)}

J. Chezel ${ }^{1}$, N. Costedoat-Chalumeau², D. Rouzaud ${ }^{1}$, V. Le Guern ${ }^{2}$, C. Gobeaux ${ }^{2}$, N. Morel ${ }^{2}$, M. Pha ${ }^{3}$, Z. Amoura ${ }^{3}$, T. Papo ${ }^{1}$, K. Sacre on behalf of PLUS group. ${ }^{1}$ Université Paris Diderot, Paris, France; ${ }^{2}$ Université Paris Descartes, Paris, France $;^{3}$ Université Pierre et Marie Curie, Paris, France

Background: Mortality is still 2 to 5 times superior in SLE patients as compared to general population and is mainly due to cardiovascular event (CVE). Although cardiovascular traditional risk factors contribute to early-onset atherosclerosis in SLE, the phenomenon is not fully explained by a higher frequency of smoking habits, hypertension, or dyslipidemia and the Framingham risk equation usually underestimates the 10-year cardiovascular risk in this population. Thus, identification of biological markers able to better stratify cardiovascular risks in SLE patients is needed.

Objectives: Our study aimed to determine whether serum cardiac troponin $T$ measured with a highly sensitive assay (HS-CTnT) was associated with CVE in systemic lupus erythematosus (SLE) patients.

Methods: All SLE patients included between 2007 and 2010 in the randomized, double-blind, placebo-controlled, multicenter PLUS trial were retrospectively screened. Patients with no past history of CVE and a follow-up period of $>20$ months were analyzed. HS-cTnT concentration was measured using the electrochemiluminescence method on serum collected at PLUS inclusion. The primary outcome was the incident CVE. Factors associated with the primary outcome were identified and multivariate analysis was performed.

Results: Overall, 442 SLE patients (of the 573 included in the PLUS study) were analyzed for the primary outcome with a median follow up of 110 (IQR: 99-120) months. Among them $29(6.6 \%)$ experienced at least one CVE that occurred at a median of 67 (IQR: 31-91) months after inclusion. Six out of 29 patients had more than one CVE. In the multivariate analysis, dyslipidemia, duration of SLE disease and HS-cTnT were associated with the occurrence of CVE. Kaplan-Meier analysis showed that a concentration of HS-cTnT>4.27 ng/L at inclusion increased by 2.7 (HR 2.7 [1.3-5.6], $\mathrm{p}=0.0083$ ) the risk of CVE in SLE.

Conclusion: HS-cTnT measured in serum is the first identified biomarker independently associated with incident CVE in SLE patients

Disclosure of Interests: Julie Chezel: None declared, Nathalie Costedoat-Chalumeau Grant/research support from: UCB to my institution, Diane Rouzaud: None declared, Véronique LE GUERN Grant/research support from: UCB for GR2 study (to our institution), Camille Gobeaux: None declared, Nathalie Morel: None declared, Micheline Pha: None declared, Zahir Amoura: None declared, Thomas Papo: None declared, karim sacre: None declared DOI: 10.1136/annrheumdis-2020-eular.350

\section{SAT0202 \\ C4 LEVELS AS PREDICTOR OF DISEASE FLARES AND ADVERSE PREGNANCY OUTCOMES IN SYSTEMIC LUPUS ERYTHEMATOSUS PREGNANCIES}

F. Crisafulli ${ }^{1}$, M. C. Gerardi ${ }^{1}$, M. Filippini ${ }^{1}$, R. Gorla ${ }^{1}$, M. Fredi ${ }^{1}$, M. G. Lazzaroni ${ }^{1}$, M. Taglietti ${ }^{1}$, C. Nalli ${ }^{1}$, S. Zatti ${ }^{2}$, C. Zanardini ${ }^{2}$, A. Lojacono ${ }^{2}$ L. Andreoli ${ }^{1}$, F. Franceschini ${ }^{1}$, A. Tincani ${ }^{1} .{ }^{1}$ ASST Spedali Civili and University of Brescia, Rheumatology and Clinical Immunology Unit, Brescia, Italy; ${ }^{2}$ ASST Spedali Civili and University of Brescia, Obstetrics and Gynaecology Unit, Brescia, Italy

Background: SLE pregnancies have an increased risk of Adverse Pregnancy Outcomes (APO). In clinical practice, low C3 and C4 levels are associated with active disease and, during pregnancy, complement activation products are shown to be associated with APO.

Objectives: To analyse potential association between $\mathrm{C} 3$ and $\mathrm{C} 4$ variations and disease flares and APO during SLE pregnancies.

Methods: Demographic, clinical and laboratory data on SLE pregnancies prospectively-followed by a multidisciplinary team in a pregnancy clinic from 1987 to 2015 were retrospectively analysed at preconception and at each trimester. Hypocomplementemia was defined according to the normality range calculated in healthy pregnancies by Reggia et $\mathrm{al}^{1}$. APO were defined as: early miscarriage $\left(<10^{\text {th }}\right.$ week), intrauterine fetal death $\left(>10^{\text {th }}\right.$ week $)$, perinatal death $\left(<30^{\text {th }}\right.$ day of life), pre-eclampsia (PE), severe preterm birth $\left(<34^{\text {th }}\right.$ week).

Results: 134 pregnancies in 98 SLE patients were analysed. APO occurred in $22(16 \%)$ pregnancies: 9 early miscarriages, 4 intrauterine fetal deaths, 3 severe preterm births, $6 \mathrm{PE}$ (hesitated in 1 intrauterine fetal death, 1 perinatal death; 2 preterm birth between $34^{\text {th }}$ and $37^{\text {th }}$ weeks and 2 term births). 13 flares
(2 renal, 4 articular, 6 cutaneous and 1 neurological) were recorded in $11(8 \%)$ pregnancies.

The mean $\mathrm{C} 3$ and $\mathrm{C} 4$ levels at each trimester are shown in table 1.

Table 1. C3 and C4 mean levels $(\mathrm{mg} / \mathrm{dL})$ at pre-conceptional visit $(\mathrm{TO}), 1^{\text {st }}$ trimester (T1), $2^{\text {nd }}$ trimester (T2) and $3^{\text {rd }}$ trimester (T3).

\begin{tabular}{|c|c|c|c|c|c|c|c|}
\hline & C3 T0 & C3 T1 & C3 T2 & C3 T3 & p T0-T1 & p T1-T2 & p T2-T3 \\
\hline Pregnancies with flares & 73.2 & 82.2 & 83.8 & 97.5 & 0.04 & 0.02 & 0.06 \\
\hline Pregnancies without flares & 85.3 & 91.8 & 104.4 & 114.7 & $<0.001$ & $<0.001$ & $<0.001$ \\
\hline Pregnancies with APO* & 84.7 & 91.5 & 98.5 & 106.3 & 0.03 & 0.03 & 0.89 \\
\hline Pregnancies without APO* & $\begin{array}{c}84.5 \\
\text { C4 T0 }\end{array}$ & $\begin{array}{c}90.9 \\
\text { C4 T1 }\end{array}$ & $\begin{array}{l}102.8 \\
\text { C4 T2 }\end{array}$ & $\begin{array}{l}112.8 \\
\text { C4 T3 }\end{array}$ & $\begin{array}{l}<0.001 \\
p \text { T0-T1 }\end{array}$ & $\begin{array}{l}<0.001 \\
\text { p T1-T2 }\end{array}$ & $\begin{array}{l}<0.001 \\
p \text { T2-T3 }\end{array}$ \\
\hline Pregnancies with flares & 8.6 & 11.8 & 10.9 & 11.4 & 0.01 & 0.43 & 0.27 \\
\hline Pregnancies without flares & 13.2 & 14.7 & 16.3 & 16.6 & $<0.001$ & $<0.001$ & 0.98 \\
\hline Pregnancies with APO** & 13.1 & 16.1 & 15.9 & 14.7 & 0.01 & 0.3 & 0.13 \\
\hline Pregnancies without $A P O^{* *}$ & 12.9 & 14.2 & 15.8 & 16.1 & $<0.001$ & $<0.001$ & 0.42 \\
\hline
\end{tabular}

Comparison of $\mathrm{C} 3$ and $\mathrm{C} 4$ mean levels between pregnancies with APO vs without APO:

* T0, T1, T2, T3: ns; ** T0, T1, T2, T3: ns

Both in pregnancies with flares and with APO, there was no increase of $\mathrm{C} 3$ between the $2^{\text {nd }}$ and the $3^{\text {rd }}$ trimester and of $\mathrm{C} 4$ between the $1^{\text {st }}$ and the $2^{\text {nd }}$ trimester.

At preconception, mean levels of $\mathrm{C} 4$ were lower in pregnancies with flares compared to those without flares (images 1 and 2); during the $2^{\text {nd }}$ and the $3^{\text {rd }}$ trimesters the mean levels of both $\mathrm{C} 3$ and $\mathrm{C} 4$ were lower in pregnancies with flares.

In pregnancies with APO, the variation of C4 levels between the $2^{\text {nd }}$ and the $3^{\text {rd }}$ trimester was lower than in pregnancies without APO ( -3.18 vs $0.27 ; p=0.01)$

A higher frequency of low C4 was observed at pre-conceptional visit, $1^{\text {st }}$ trimester and $3^{\text {rd }}$ trimester (6/7 vs $25 / 103 p=0.002 ; 8 / 9$ vs 56/106 $p=0.04 ; 9 / 11$ vs $33 / 96 p=0.003$ ) in pregnancies with flare as compared with pregnancies without flares.

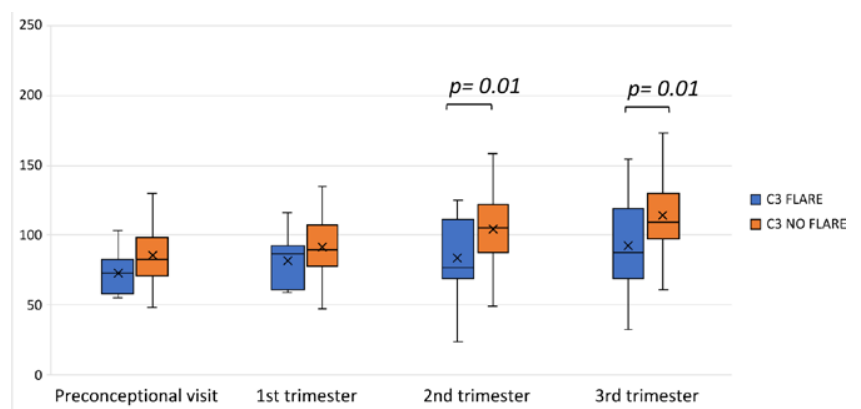

Figure 1. Image 1: comparison of C3 mean levels between pregnancies with fares vs without flares

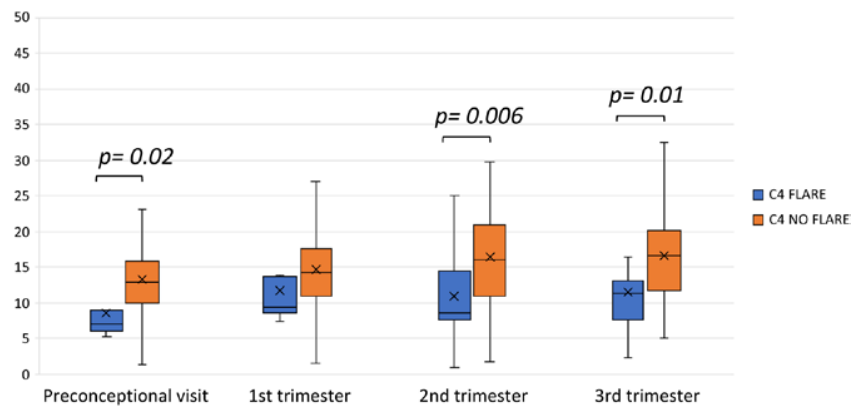

Figure 2. Image 2: comparison of C4 mean levels between pregnancies with fares vs without flares

Conclusion: In our cohort of prospectively-followed SLE pregnancies, low C4 levels at preconception seems to predict flares during pregnancy. Low increase of C4 levels between the $2^{\text {nd }}$ and the $3^{\text {rd }}$ trimester could predict an APO.

\section{References:}

[1] Reggia R. et al. Rheumatology 2012;51:2186-90

Disclosure of Interests: None declared

DOI: 10.1136/annrheumdis-2020-eular.6365 